\title{
Natural(ly) men: masculinity and gendered anti-ageing practices in Finland and the USA
}

\author{
HANNA OJALA*, TONI CALASANTI $\dagger$, NEAL KING $\dagger$ \\ and ILKKA PIETILÄ
}

\begin{abstract}
The neo-liberal ideologies that point to individual responsibility for risks increasingly influence countries of the global North. The anti-ageing industry reflects this dictate and encourages middle-aged people to use their products and services to manage their ageing. However, given the negative connotations attached to the term 'antiageing', which is usually seen to focus on aesthetics and thus be a woman's concern, men may be likely to disavow being involved in such activities. The article uses interview data collected from men aged $42^{2}-70$ from Finland and the United States of America to explore whether and how men adhere to the call to manage their ageing when such anti-ageing activities are seen to be potentially feminising. We find that these men reflected neo-liberalism in the sense that they felt that, although ageing cannot be prevented, it can be controlled. Also while they generally rejected antiageing products and services that they judged to affect aesthetics, they reported that they use those that they define as promoting health and performance instead. For them, masculinity is the instrumental focus on performance to the exclusion of beauty or attractiveness. Masculine anti-ageing bodily strategies must also be 'natural', involving hard work rather than the use of products, which they regard as never having been scientifically proven to enhance performance. Thus, in talk of their antiageing, men distance themselves from women.
\end{abstract}

KEY WORDS - anti-ageing, global North, gender, men, masculinity.

\section{Introduction}

Middle-age masculinity of the global North operates in the context of neoliberal age relations. The neo-liberal ideologies that attach moral value to the individual (George and Whitehouse 2011), and which point to individual

* School of Social Sciences and Humanities, University of Tampere, Finland.

$\dagger$ Department of Sociology, Virginia Tech, Blacksburg, Virginia, USA.

* School of Health Sciences and Gerontology Research Center, University of Tampere, Finland. 
responsibility for risks previously assumed by the larger group, increasingly inform policies and mundane activities in the global North (Phillipson 2009). Among other outcomes, this has resulted in greater emphasis on personal control of bodies, and use of the 'marketplace ... [to] make himself [sic] whole' (George and Whitehouse 2011: 592). Viewing the body as an 'open-ended' project 'implies that it is open to reconstruction in line with the designs of its owner' and that these desires emerge from both 'aesthetic and health-related imperatives' (Petersen and Lupton 1996: 23).

Within the age relations of such societies, people associate ageing with bodily decline, gauge the extent to which a body looks young or old, and assess health on that basis. At the same time, people link health to morality, holding each other responsible for sustaining healthy lifestyles (Conrad 1994; Crawford 1994). To the extent that groups treat good health as being under the control of individuals and something that can be inferred from how bodies look and act, then bodies that appear to be old may draw rejection or rebuke. Even age peers will distance themselves from others they deem to be 'old' (Hurd 1999; Minichiello, Browne and Kendig 2000; Townsend, Godfrey and Denby 2006).

The ways in which bodies are marked or experienced as 'old' may vary by the intersections of gender, race, ethnicity, class and sexual orientation, but discrimination results nonetheless. In anticipation or response, ageing people may try to present their bodies in ways that avoid inspiring ageism. Such regulation and alteration of bodies occurs in the context of what is commonly called the 'anti-ageing industry', a commercial and clinical industry that 'offers anti-ageing products, regimens, and treatments' touted to forestall or even reverse ageing (Binstock, Fishman and Johnson 2006: $43^{6}$ ). The massive global appeal of this industry is apparent in its popularity and profitability. According to the market forecasting firm Business Communications Company, which considered products and services related to health maintenance, appearance and fitness in its market forecast, the global anti-ageing market was worth US \$162.2 billion in 2008, and was predicted to reach US $\$ 274.5$ billion in 2013. While the anti-ageing industry's presence is greatest in the United States of America (USA), contemporary Europeans have shown great interest as well, and anti-ageing centres can be found in many European and Asian countries (Binstock, Fishman and Johnson 20o6: 439).

\section{Anti-ageing as a gendered practice}

People often begin to consult anti-ageing practitioners to help 'manage' their ageing bodies in middle age, as this is a time in which they become 


\section{$35^{8}$ Hanna Ojala et al.}

increasingly aware of their bodily changes (Fishman, Settersten and Flatt 2010). Although such management can include a broad range of activities that target diverse aspects of lifestyle and the self, the general public often sees 'anti-ageing' as focusing on aesthetics: beauty, impressiveness and youthful appearance (Fishman, Settersten and Flatt 2010). Because most people take beauty (the deliberate grooming of one's appearance to please others) to be a woman's concern, they, and especially men among them, are not likely to see themselves as engaged in anti-ageing.

Indeed, research makes clear that anti-ageing products and services are often marketed to women and focus on providing visual pleasure (Calasanti 2007). In this regard, women's sense of selves as women rests on their attractiveness to men, and anti-ageing purveyors depict women's bodies as being 'at risk' of failing in this regard and therefore in need of the intervention provided by their products and services (Smirnova 2012). Such concerns and motivations are reflected in studies of women's use of a range of surgical and non-surgical cosmetic procedures (e.g. Brooks 2010; Hurd Clarke 2011; Smirnova 2012 ).

At the same time, women discriminate among their available anti-ageing options in terms of how natural they are (Smirnova 2012). Such notions of 'natural' have at least two referents, as Hurd Clarke and Griffin's (2007) interview study of women's anti-ageing practice shows. The first has to do with 'natural' ageing for women. The women in their study felt their ageing naturally to be risky, their appearances decreasingly beautiful, and as a result saw the use of cosmetics, anti-wrinkle creams and hair treatments as normative for women, even needed. However, their discussion of such interventions made clear a second way in which they thought about 'natural' or 'unnatural' ageing. That is, the women distinguished between good and bad interventions based on how natural-looking the end result was, as well as how easily others were able to detect whether or not the woman had used nonsurgical and surgical cosmetic interventions (Hurd Clarke and Griffin 2007).

The neo-liberal dictate to exert personal control over bodies with the help of the anti-ageing industry, on the one hand, and the public alignment of anti-ageing with beauty and women, on the other, raises the question of how ageing men deal with these seemingly contradictory pressures. The extent to which men consume anti-ageing products and services as men remains largely unknown. Hurd Clarke and Korotchenko (2011: 500) make clear that the majority of research on men and body image focuses on younger men, and that none looks at older men's experiences of what they call 'appearance work' - 'the use of clothing, cosmetics, dieting, exercise, hair care and other similar practices to maintain or alter one's appearance'. But the persistent marketing of anti-ageing products to men in terms of staying and playing hard (avoiding grey hair, muscle loss, reductions of 
aggressiveness and impotence; Calasanti and King 2005) suggests that men might feel their status as competently gendered people threatened by the changes that ageing includes.

Theories of gender as omnirelevant (West and Zimmerman 1987) and masculinity as a mainstay of gender privilege (Connell 1995; Connell and Messerschmidt 2005) would lead us to expect that ageing men would avail themselves of some anti-ageing but would distance themselves from women and beauty as they patronised the industry. We define masculinity as all that groups do to keep men distinct from other groups and from incompetence, holding organisations and members accountable to the standard of conducting their activity in sex-specific ways. They do this by dividing paid labour and many other activities along gendered lines, allowing for the crossing of lines so long as members account for the deviations somehow, as exceptions or as deliberate violations (West and Zimmerman 1987).

We theorise masculinity on the basis of the political economy of gender, intersecting as it does with such other inequities as race, sex and class (King and Calasanti 2013). Manhood, the categorical status that this group activity reifies, becomes more salient and influential when political economies split parenting from the production of wealth, excluding mothers from some or much of the latter, and leading to policies which exclude women in general (Collins et al. 1993). In many such political economies, women must rely upon men to share the goods they produce or currency they earn, and provide care to others in exchange for that sustenance. Men may, in turn, receive such care either for free from female lovers or kin, or at little cost from the care industries that employ (mostly) women.

Such gendered political economies distinguish men from others with skilland-task orientations that avoid both open expressions of vulnerability and primary responsibility for empathetic concern-duties and demeanours ascribed to women. These include activities designed to provide pleasure to others: nurturance, beauty, and other forms of pleasure and care. Men who fail to maintain such orientations must either account for the deviations (posing them as exceptions or deliberate rebellions) or risk appearing either incompetent or, in an extreme cases, not to be men anymore.

Such distinctions are consistent with analyses of anti-ageing advertisements in the USA, which suggest that the masculinity sold is one that stands in overt contrast to femininity and to weakness, and emphasises performance, competition with other men at work and at play, and dominance over women (Calasanti and King 2007). This manhood remains distanced from such beauty-oriented activity as dieting, and remains focused on being more impressive instead, on the spectacles of strength or power, conveyed terms of mechanical function and health that allow men to produce and to rule rather than to provide pleasure or care to others (Hurd Clarke and 
Korotchencko 2011; Lodge and Umberson 2013; Solimeo 2008). One respondent, quoted in Slevin (2008: 39), specifies the function of a car that one oils, greases and repairs. Kinnunen (2010) found that, of a small number of Finns who reported having cosmetic surgery, the only two men both focused on performance, wanting to look like they were active and good workers. Such sentiments are similar to what is generally reported in the USA (e.g. King and Calasanti 2006).

The goal of our study is to explore men's use of anti-ageing products and services in relation to these ideals of manhood and personal control over bodily ageing in the effort to avoid ageism. We focus only on those antiageing strategies that are geared at appearance, which potentially create the greatest tensions in the maintenance of a relatively privileged status - to fight age and to enact masculinity. Ideals of manhood are based on the activities of youth (Calasanti 2007) and in opposition to femininity. Ageing men thus distance themselves from two devalued categories: women and old people. Our concern is not so much on the extent to which they use these products and services as on how they relate them to manhood.

Our analysis draws from samples of middle-aged and aged men in Finland and the USA. As we describe below, the studies in Finland and the USA both asked respondents about their anti-ageing practices, and thus allow us to explore how middle-aged and aged men use (or refuse) anti-ageing products in relation to their senses of selves as men. Finland and the USA share the neo-liberal emphases on personal responsibility and control upon which the anti-ageing industry draws. Although anti-ageing products and services are not as numerous in Finland as in many other countries, they are increasingly prevalent. In addition to their ability to access products from the USA, Europe and Asia, Finns have their own lines of anti-ageing products and services, as seen by the marketing of such products as Xocai, a 'healthy chocolate' that is said to have anti-ageing properties (Adam Paul Green 2014 ); the recent launch of anti-ageing beauty products by Lumene (Racked 2014) and Sesderma (Sesderma 2014); and the prevalence of skin-care clinics (Intraceuticals 2014). The World Society Interdisciplinary Anti-Aging website, which purports to be 'the World's fastest growing Anti-Aging Medicine Society', lists 16 members in Finland (WOSAAM 2014). These include not just cosmetic surgeons and dermatologists, but also a gynaecologist and a medical practitioner who simply lists anti-ageing as the specialty. Therefore we do not expect the countries to differ significantly in how people, as consumers, perceive the anti-ageing products and services. Previous research on ageing, health and masculinities has found no major differences between US and Finnish men in these respects (Calasanti et al. 2013). At the same time, we note the country in question throughout our analysis so that similarities and differences can be assessed. 


\section{Materials and methods}

For the purposes of this study we analysed a combined set of thematic personal interviews $(\mathrm{N}=32)$ and focus groups $(\mathrm{N}=8)$ conducted with $4^{2-70-y e a r-o l d ~ m e n ~ i n ~ F i n l a n d ~ a n d ~ t h e ~ U S A . ~ T h e ~ F i n n i s h ~ i n t e r v i e w e e s ~}$ comprised metal workers (12 men) and engineers (11 men), while the men from the USA $(\mathrm{N}=9)$ represented a range of occupational types (five professionals, two semi-professionals and two working class). The data collection for each country's sample is described more thoroughly below. Methodologically, the study is informed by thematic analysis (Luborsky 1994) and critical discursive psychology (e.g. Edley and Wetherell 1997; Wetherell and Edley 1999). Prior to our analysis of the combined data, the two pairs of authors had conducted their separate studies of the Finnish and US data, and had noticed similar patterns in respondents' perceptions of their bodies, age-based changes to them and ways to respond. A team approach to the study of the pooled data, developed over the course of a series of meetings and based on consensus, was then used to compare patterns among the two sets of respondents (Luborsky 1994).

The Finnish data consisted of employed men aged $5^{\mathrm{O}-55}$, who were approaching retirement age, and retired men, aged $65^{-} 70$, who had retired five to seven years earlier. The sample included 12 metal workers (six working, six retired) and 11 engineers (four working, seven retired). The metal workers were recruited via the local office of the labour union, which organises recreation activities for its retired members, whereas the engineers were invited to join the research via a local association of engineers. These two, male-dominated occupational groups were chosen based on considerations of class. As a traditional, manual, industrial and male-dominated occupation, metal workers represent vocationally educated working-class men, whereas engineers are more highly educated (Master of Science) and work as professionals (e.g. managers) in the fields of technology and the built environment, and thus represent middle-class men.

Respondents were interviewed both in focus groups (two focus groups were organised for each occupational group) and in personal interviews (at least twice, usually three times). The fourth author and a female undergraduate student conducted the metal workers' interviews in spring 2010 , and the first and fourth authors interviewed the engineers in autumn 2011. The overall topic of interviews and focus groups was men's ageing, including several themes that ranged from health, bodily ailments and health-related behaviours to social relationships and psycho-social wellbeing. Respondents were also asked about their ideas concerning how to slow down ageing and their consumption of various anti-ageing products. All interviews were 
digitally recorded and transcribed verbatim with a signed informed consent from the interviewees.

The data on US men are derived from a larger sample of in-depth interviews conducted among 19 men and women. An attempt was made to diversify the sample; as a result, the nine men used in this study include not only working-class and professional men, but also men who are presently married (five), divorced (one) and never married (three), including two who identify as non-heterosexual. The professional men (five) all had education beyond the college degree; of the remaining four respondents, only one had graduated from college, while the other three had completed high school or some college. All the men were white.

The goal of the interviews was to understand how ageism, age relations and gender influence men's and women's experiences of their ageing bodies. Questions thus sought to explore bodily changes that they had experienced, and their feelings about these; what it means to act and look good for one's age; awareness of their own age and that of others; and positives and negatives about being middle-aged. The interviews also explored whether or not they pursued anti-ageing strategies, and why or why not; and thoughts about their future ageing, including hopes as well as concerns. Most interviews took at least two hours (though one lasted only 45 minutes), with a few lasting three hours. After receiving signed informed consent, the second author conducted all the interviews but one, which was carried out by a female graduate student; all occurred at a location of the respondent's choosing. Interviews were recorded and transcribed professionally, and then coded thematically.

The analytic strategy involved a creative process of inductive reasoning and theorising. Data were collected and analysed in an iterative process, leading to the development of new questions in later interviews (Taylor and Bogdan 1998). The second author derived an initial code sheet, which was developed further over the course of time and more interviews, and in conjunction with input from two other researchers who read key interviews independently. We used QSR NUD*IST 6.o to examine further themes already delineated. This software did not guide the analysis per se but provided ancillary help.

Although the data-sets used in this article were not collected originally with an eye towards research collaboration, the topics discussed (ageing, bodies, health in relation to masculinity and anti-ageing practices) were sufficiently similar that we can treat our data-sets as a body of men's talk on ageing and managing it in two contemporary anti-ageing national cultures in the global North. Both data-sets included questions about the respondents' knowledge, possible use, and attitudes to anti-ageing products and services. Initial analysis demonstrated no significant differences between the data-sets 
(focus groups versus personal interviews; USA versus Finland), but in reporting the findings we list sample characteristics in cases where they are relevant for interpreting the results.

In analysing our respective data, we focused on gendered elements of the men's negotiations concerning use or non-use of anti-ageing products, cultural expectations linked to men's experiences and how they locate themselves as men in fight against ageing. We explored both explicit and implicit statements that men expressed either supporting or opposing the use of anti-ageing products, as well as on gendered features that they attached to their use. Interestingly, the respondents in both countries often talked about their ageing bodies and anti-ageing strategies in terms of 'natural', 'unnatural' and 'artificial', very much in line with the women in Hurd Clarke and Griffin's (2007) study. Thus, our analysis also uses the distinctions of 'natural' ageing and 'natural' interventions that they use.

Below, we first explore the ways interviewees define some anti-ageing practices as appropriate and thus 'natural' for men. We discuss the extent to which these men believe in notions of personal control in relation to their ageing bodies generally, and then we describe their thoughts about antiageing goods and services specifically. Next, we illustrate how men actually engage in anti-ageing strategies and describe their anti-ageing practices. In this regard, we focus on how interviewees construct masculinity in relation to their ideas about 'natural' approaches and their use of anti-ageing products and services.

\section{Natural acts versus bluff products}

Yeah I certainly make an effort, but I will not do anything that isn't natural. (Greg, ${ }^{1}$ USA, age 61)

Men from both countries mentioned anti-wrinkle creams, cosmetics, hair dyes, and herbal supplements and drugs as means to slow down the effects of ageing. Men from the USA also referred to non-surgical cosmetic procedures (like Botox and Restilin); and men in both samples mentioned cosmetic surgeries. Both Finnish and US interviewees said that they could slow the effects of ageing, and often expressed their sentiments in a strong manner: 'I've got 1 oo per cent confidence', 'absolutely', 'of course', 'I think I can' and 'damn sure you can', expressions were characterised by 'extreme case formulations' (Pomerantz 1986). However, they rejected many of the anti-ageing products that they mentioned, both as related to beauty and as

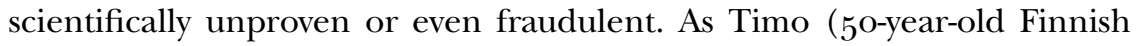
metal worker) says 'I think they [anti-ageing products] are pretty much bluff, at least the majority of them, they must be because they are not all 


\section{Hanna Ojala et al.}

medically studied and proved'. Men knew of these products through advertisements and everyday situations, most often their own wives' beauty work; but they excluded such products from their own lives.

What men see as 'natural' methods for forestalling ageing are themselves gendered. The men held negative views of cosmetic surgery as an unnatural means to fight ageing, aligning it with women and femininity. When men do use the same anti-ageing products and services as women do, they still distinguish the kinds that they buy and ways in which they employ them. The focus group discussion of Finnish retired engineers in relation to facial creams provides an example.

[the group is discussing anti-ageing products, particularly skin-care products]

Aarne: $\quad$ My wife always says...

Jyrki: $\quad$ It's women's stuff.

Aarne: $\quad$...that your skin is a bit dry, 'let me put a bit of it there in your cheeks there' and I say 'do you really need to, well OK, do it then if you need to'. I think it's disgusting but it's always that if she puts it then I have to rub it in (laughing). She said that, that your skin gets wrinkly or say, like old-looking, if you don't use it. But I don't myself' cause ... you don't see your own skin and then as you have bad sight so if you look in the mirror you don't really see it that sharply so that... (smiling)

Ilmari: Yes, well yes, well it's a bit like kind of women's stuff. To me [someone says yes] it's like, I use, like when I sweat. If I go out jogging or have $30-40$ minutes training on an exercise cycle so that when I really sweat then after that ... It's because I have sort of dry skin so that ... It's one of those unscented. . .

Aarne: $\quad$ Yes it's...

Ilmari: $\quad$ cream, which I use.

Aarne: $\quad$ namely the drying of skin, that's why the wife ... that moisture. So that she, like 'your skin looks too dry', she looks at it. It doesn't feel dry to me! (laughs)

Ilmari: $\quad$ You feel it yourself when, or at least I feel that now it's so damn dry ... Then I just put a bit of cream to my face and that's it.

Johannes: Oh yes, taking care of your feet, for instance, surely starts earlier than skin care.

All together: Umm, aye. Yes.

Johannes: It's like a practical reason.

The excerpt starts with Aarne's story about how his wife pays attention to his skin's dryness, giving instructions how to deal with it ('your skin gets wrinkly or say, like old-looking, if you don't use it'), and taking the initiative to put moisturiser on his cheeks. The husband lets the wife to do that, even if not 
accepting the idea. He justified his refusal of a moisturiser by telling how it feels 'disgusting' and how use of it would conflict with his sense of his body: his skin 'doesn't feel dry'.

These men share an understanding of anti-ageing as 'women's stuff', which they construct in collaborative exchanges among themselves. After Aarne's account, Ilmari continues the same line of thinking, emphasising that the use of skin-care products is more a matter of feelings ('you feel it yourself') related to health or performance than aesthetics. Exercise and sweating dries the skin - and makes it feel dry - which is the reason for Ilmari to cream his face. By the end of the excerpt, this reason to use skin-care products is crystallised by Johannes: 'It's like a practical reason'.

Derision of women's skin-care products does not necessarily prevent men from using creams. Like Ilmari, men can justify their use in ways that distance them from women. They describe their moisturisers as 'basic', 'ordinary' and 'natural' ('one of those unscented'), and rationalise their care for their skin in terms of sweaty exercise and their inner feelings. This gives 'a practical reason' for the use of moisturisers, which distinguishes men's motives from women's beauty practices. The idea is that men do not use the skin-care products to provide visual pleasure for others. This also constructs men as agents independent of influences of marketing and other external motives.

In some cases, men distance themselves from even the most basic products, as Finnish 65-year-old retired metal worker Asko demonstrates:

Interviewer: Well have you noticed that your wife would use them [antiageing products]?

Asko: Not her either. Well sure, she's got those creams and sort, they're something what are they. But I told the wife that basically it's the good Finnish soap [that matters]. And then I myself don't ... I wash every evening and every morning my face and all. But I don't use soap. I wash up naturally. Many have only wondered why is it so that you don't have any wrinkles. I've got the natural fat in here [face] and I just wash the dirt away, and that's true. The grandchildren also have such fine hair and all. They don't use any shampoo because they wash up, they go to sauna several times a week.

In his account, Asko takes the notion of naturalness to an extreme, maintaining distance from nearly all cosmetic products, even most soap. Asko's description of how he washes himself is typical of Finnish metal workers' accounts of practices relating to appearance. Men distinguish practices-particularly those between men and women-explicitly and with extreme case formulations (Pomerantz 1986), such as 'every evening and every morning', 'any wrinkles', 'fine hair and alt, which sharpen the 
distinctions. Asko claims that others' comments about his few wrinkles attest how ideal pure water is for fighting ageing. Asko distances himself from vain women, including his wife, who use artificial products, believe empty promises of advertisements and waste their money.

Men in this study emphasised the importance of physical exercise (e.g. gym training, jogging), healthy diet (including vitamins), as well as sleep and rest as a 'natural way' to control ageing (see also Calasanti et al. 2013). They point to these as natural and justified means to slow ageing, and contrast them to the artificial products that lack scientific proof for their vendors' claims.

Greg (USA, age 61) makes clear that, to him, the differences between natural and artificial approaches to anti-ageing relate to effort: 'I subscribe to the fact it requires work ... It does not come in a bottle or it does not come in a pill.' Similarly Asko comments on the doubtfulness of these latter products:

There are magazines more or less full of these pills ... All these famous persons are [advertising them], sort of [if you use these products] you jump out of bed like a kangaroo in the morning. But I don't believe that, because it's just that if you have problems with your joints and aches and such, they won't go away with just one pill'.

In the next excerpt $5^{1-y e a r-o l d ~ J a k e ~(U S A) ~ u n d e r l i n e s ~ t h e ~ i m p o r t a n c e ~ o f ~}$ naturalness and continuous monitoring of diet.

Interviewer: Do you modify or monitor your diet?

Jake: $\quad$ Not so much, but if I had to say I'd say 10 per cent because I will, I don't eat desserts, don't like chocolates, I cut out Cokes a long time ago, I drink Diet Coke ... That's what keeps me from getting all my goals.

Interviewer: Right.

Jake: $\quad$ That's why I'm not 190 pounds and 'ripped' is because of my diet. $[\ldots]$

Interviewer: Okay. Do you take vitamins, minerals, other supplements?

Jake: $\quad$ I do, and uhm, vitamins I probably take a month out of the year because I just can't stand them.

Interviewer: Okay.

Jake: $\quad$ And pills I just can't stand. This stuff that I mix with my drinks, protein, and they are just, I guess like you say recovery drink.

Interviewer: Okay. Are there any herbal extracts that you use?

Jake: No. [I'm] very interested in those though because that would be a good natural way to do a lot of things that we do harsher stuff [for] that probably [we] wouldn't have to.

For Jake - who is highly engaged in physical exercise - the right way to deal with ageing is proper diet (avoiding sugars) and hard body work. Although Jake says he monitors his diet, he gives a long list of 'prohibited' foods and 
concludes that not avoiding them enough is 'what keeps me from getting all my goals'. And as evidence for the efficacy of training and diet, Jake refers to his weight, which, along with greying, is the other concern that men noted. Here again, however, the reference to weight is clearly distinguished from women's realm by reference to health rather than beauty. The scant research on older men and appearance work notes that while men may be concerned about body weight (e.g. Slevin 2008), they reject dieting as 'feminine'. Instead, when they engage in dieting, they say that it is for reasons of health and not weight loss per se (Hurd Clarke and Korotchenko 2011).

\section{Letting nature take its course}

Although men in both samples distanced themselves from anti-ageing products, they did not ignore how their ageing bodies appeared to others. Instead, they distinguish the overt maintenance of youthful beauty, an activity they impute to women, from their own care for their health and physical abilities. Manhood is based in part on the impressions of power and skill that can ground claims to privileged roles in governance and the production of wealth. This masculine approach to appearance becomes clearer in relation to two experiences that challenged the men to consider the effects of ageing on their bodies' appearance as well as means to influence this process: becoming overweight and seeing their hair grey.

In the excerpt below, Jake contemplates how grey hair can be a concern for men, in contrast with wrinkles, which he regards as an issue for women:

I mean maybe I'm on the wrong thought here, but like what I would see for a woman is the wrinkles would be a thing a guy probably wouldn't worry so much about. Hair, I think, a guy worries about, weight probably I think a guy worries about a little bit more, whereas, like, for you [female interviewer] to colour your hair or [my wife] to colour her hair or Lisa to colour her hair is just cool. For me to colour my hair would probably be, 'man, you probably shouldn't do that', you know? And I'm not sure if it's just the products we're using or what, but I mean I don't know too many guys that I know that colour their hair that I would say was probably a good idea.

Having hair that is greying seems unpleasant for Jake; however, hair colouring is not a solution because, in his view, men should leave such products to women. As John (USA, 45 years, professional) puts it,

[y] ou know I think people would look differently at a man when they know he coloured his hair than they would a woman if they know she coloured her hair ... [I] t could ... be that when a man does it he's taking on, he's doing feminised activities. That is he's doing something a woman would do and so that ... there could also be that kind of [concern with] what it takes to be an authentic male.

For most men, dying hair to get rid of grey is 'gender transgressive behaviour' (Henwood, Gill and McLean 2002), which oversteps gender norms and 
makes men vulnerable to rebuke from other men: 'man, you probably shouldn't do that'. To that extent, engagement in anti-ageing practices occurs in a context in which other men's reactions are taken into account. Finnish retired engineer Mauri (age 66) similarly considers the social implications of colouring hair.

Interviewer: Have you thought about how your appearance changes by ageing?

Mauri: I thought about it earlier but not so much anymore. When the first grey hair started to appear, well those days I thought like 'wow', sort of, when my chin got grey, even quite rapidly ... But I've not worried about it anymore. Balding proceeds all the time, but I've not thought about it like it was, it just belongs to this life. Let it be, it's more like, how would you say it ... it's a marker of lived life ... Once I got shocked, 'cause I had a totally grey colleague, I was used to his greyness, well one day he had a black beard!

Interviewer: So that he had...

Mauri: $\quad$ Yes, he had made his beard all black.

Interviewer: Oh my...

Mauri: $\quad$ Yes it is. OK, what's of it, sure. I have not felt like I should be sort of, something else than I am ... If I suddenly decided that 'OK, now I'm going to colour my hair, and colour my beard', and then I would go to meet folks and see what they'd think about it, say about it. [Their reaction] could be a bit like 'wow', and it could also be awful if someone sort of tried to be younger than he was. And it's the same with, everybody dresses the way he wants ... You certainly understand if someone feels that he's greying prematurely, so that he's starting to be grey already before $4 \mathrm{o}$, for instance. Well that may feel like, it's somewhat more understandable that he's covering it a bit.

Interviewer: Oh yes, certainly.

Mauri: $\quad$ So that if you get grey approximately, let's say at certain more normal age, then it, then it's not similarly, I guess it doesn't feel that embarrassing then.

When talking about the apparent conflict between greying of hair and purposive attempts to change one's appearance, Mauri refers to his colleague who suddenly had coloured his grey beard all black, which 'shocked' Mauri. He uses morally loaded speech, with intense emotional expressions, and draws support for his interpretations from the male interviewer, who responds to Mauri's unfolding story by saying 'oh my', 'oh yes, certainly'. 
The interaction affirms the sharing of norms of ageing manhood. Greying of hair is to be expected as a man ages; and though he may be entitled to colour it if it greys prematurely, ordinary greying poses far less of a threat to the impressiveness of the powerful and skilled man than does muscle loss or any other softening. Mauri describes meeting his colleague who has intervened in a natural process that poses no threat to his manhood as shocking, embarrassing and awful, because his having coloured his beard indicates that a man has broken norms of manhood.

John (USA, professional, age 45) summarises this situation by saying 'the reason I will never colour my beard . . is the idea that people will know I have coloured my beard. There's no natural way to make it seem like it was a natural process. I can't, you know. People are not gonna think 'oh his beard must have spontaneously become ungrey'.'

By re-colouring hair that has turned grey, a man would be seen to have intervened in his appearance for no obvious performance-based reason. As a physical and visible change caused by years of living, greying should just be tolerated and accepted by men. Mauri concludes this by saying 'let it be ... it's a marker of lived life'; in the US sample, Greg (age 61) says, 'I will take my years ... whatever the cards are dealt, that's fine with me'.

These excerpts illustrate their willingness to naturalise the greying of hair as an essential part of a man's ageing body. Appearing to hide that greying can suggest a concern with beauty that the men derogate as women's and thus unnatural and artificial. In Hurd Clarke's (2011; Hurd Clarke and Griffin 2007) interviews with US and Canadian citizens, women distinguish between what appears natural and what appears obviously to have been altered by human hands. They can explain some overt use of anti-ageing products to maintain non-functional appearance as 'natural' in the sense of not looking like too much of an intervention. By contrast, these men reject any appearance of such overt intervention with products. For them, only activities count as natural anti-ageing for men.

The exception to this general rule is the case of premature greying, which Mauri mentions in his account of a man who becomes grey in 'less than normal age'. Mauri allows that this is 'more understandable that he's covering it a bit'. A man need not tolerate otherwise 'natural' changes if they occur unnaturally soon.

\section{Real men}

The ways in which these men differentiated between natural and unnatural methods of anti-ageing was apparent in their constructions of ideal versions of men who have the 'right attitude'. Some of them called this archetype an 
'authentic male' or 'real man'. This again distances manhood from concerns with beauty and mocks anti-ageing products.

In their construction, an authentic male is aware of how other men see him and thinks about himself in relation to his age. Does he appear to age naturally, like he takes care of himself? Respondents provide stories of the violation of borders of naturalness, such as by a man who has coloured his grey beard or hair. Affective speech and strong emotional expressions displayed during these accounts show that these situations are significant for men, and that they include potential for vulnerability in relation to their peers. Breaking the rules has social consequences and may even lead to social exclusion.

Interviewer: ...You know there's a lot of cosmetics addressed for men nowadays, and lots of these, various therapies that women's been using for a longer time.

Timo: $\quad$ Aye, I read somewhere that in Sweden it's a big hit to go in a male company somewhere to a spa and have some mud masks. Well I would say nooo, it's definitely not for me. I doubt I would have too many friends at work if I said that 'let's go there' with work mates (gives short laugh) and have mud masks. It wouldn't get them excited. But then if [I suggested going] for a beer to a spa...

Interviewer: Then you'd go...

Timo: Yeah, sure.

Interviewer: So that it's not in any way topical or typical of you to use such... Timo: $\quad$ It just came to my mind when my mate got a pedicure for a Christmas present. And when he mentioned about this at work, well he heard of this for like a couple of months (chuckling).

Interviewer: Aye (chuckling).

Timo: 'Oh you went to get a pedicure then...' And that probably was, he himself said it was a fine thing ... But he really heard of this [teasing] then, so that it's...

Fifty-year-old Finnish metal worker Timo's account indicates two important controls embedded in gendered anti-ageing practices. First, by referring to newspaper articles on employees of a Swedish, male-dominated company who consider it a 'big hit' to have mud masks, Timo points to limits on appearance work imposed by working-class men. By locating men's interest in beauty in a foreign context, he underscores the impossibility of such behaviour in Finnish male-dominated workplaces and men's communities. Indeed, in Finnish culture, such a reference to Swedish men is an implicit reference to homosexuality (Juvonen 2002). Secondly, Timo tells the 
interviewer that his colleague made a mistake in telling his co-workers about the pedicure he had received as a Christmas present. This resulted in continuous teasing for a couple of months. By telling the story, Timo emphasises how strict the rules for appearance work are, which would require that a working-class man interested in such cosmetic interventions as mud masks or a pedicure does not reveal this to his peers. Breaking this rule carries the risk of a social beating (Paap 2006: $3-4$ ), or an accusation of being gay - the epitome of not being a 'real man'.

\section{Discussion}

Age relations treat older people as marginal to occupational and dating networks, stigmatising them as unattractive and unfit to do highly paid work (Calasanti 2003; King and Calasanti 2013). Those systems intersect with gender, in which men gain privilege by associating themselves with skilled, valued jobs and athletic performance, and women with sexual receptivity and display. In the intersection of age and gender, men lose much of their privileges as they grow old and face dismissal as no longer able to work at valued jobs. A large anti-ageing industry promises to restore their sexual potency and workplace assertiveness, as ways to counter the emasculating effects of old age. Ageing men face two competing temptations. They must pursue the anti-ageing strategies that they have otherwise rejected as unnatural, and, in some cases, feminine, in order to retain their privileged status as able to perform. However, they must also distance themselves from most anti-ageing activities, linked as they are to women.

The men in our study negotiated these pressures by defining both 'natural' ageing bodies and 'natural' anti-ageing strategies in genderappropriate ways. Consistent with literature reviews on ageing bodies (Hurd Clarke and Korotchenko 2011) and studies on gender and the anti-ageing industry (Calasanti and King 2007), the men in our samples distanced themselves from both women's bodily concerns, and the use of products and services judged to focus on aesthetics. While some expressed concerns about greying hair, the men saw such issues as relatively unimportant. Instead, these men focused on the twin matters of health, as a means to maintain performance, and appearance, when defined strictly in terms of bodily strength or musculature.

Consistent with research on ageing women, the Finnish and US men in this study were clear that anti-ageing bodily strategies must be 'natural'. The men take the natural to involve hard work, such as exercise and control of their bodies, rather than to include the use of such products as cosmetics, hair dyes or pills, or other means that they regard as never having been 


\section{Hanna Ojala et al.}

scientifically proven to enhance performance. Thus, in talk of their antiageing, men emphasise those activities not typical of women, and in line with ideals of masculinity. They also sometimes talk of consuming similar products as women do, at which points men construct the motives of their use in ways that distance them from womanhood (e.g. using skin-care products for 'rational', functional and practical reasons instead of for aesthetic reasons). In these ways, they distance themselves from 'anti-ageing'.

As we have shown, they sometimes enforce these rules of anti-ageing through teasing. In this context, a man who is openly interested in his beauty, who speaks of using anti-ageing products to enhance it, risks being teased as feminine and/or homosexual. Such teasing can serve as a warning to other men that they must find ways to control ageing without appearing to fuss about appearance. This norm can preserve an ageing man's 'respectability' (Skeggs 2004), particularly among the working-class men whose conceptions of the means to fight ageing revolve around hard manual work, and attempts to maintain physical functioning (Pietilä and Ojala 2011). Although our studies were not aimed at exploring class-based characteristics of anti-ageing, the Finnish data in particular showed that the working-class respondents (metal workers) expressed the most negative stands against the use of anti-ageing products whereas the working-aged middle-class interviewees (engineers) did not have such categorical attitudes. Further research would benefit from a detailed analysis of these gendered attitudes across different occupational and age groups.

Of course, what is considered 'natural' ageing, and 'natural' anti-ageing strategies, likely varies by cohort (Hurd Clarke and Griffin 2007). Certainly, Hurd Clarke (2011) found that Canadian women's acceptance of both non-surgical and surgical cosmetic procedures has increased in more recent cohorts, in part as a result of the advertising and decreasing costs of such interventions as Botox. Similar changes in definition of bodily changes and appropriate interventions are likely to occur as men's bodies increasingly become subject to dictates of idealised types and advertisements. We do not argue for a static conception of natural but instead point to the ways in which conceptions of natural reinforce (or not) both age and gender inequalities.

Along these lines, Marshall and Katz (2006) have argued that antiageing products promote sex differences by holding ageing men and women to standards of embodiment that are both youth-based and gendered. Calasanti and King (2007) also found that anti-ageing advertisements stressed women's beauty and men's virility, reinforcing heterosexuality, and gender and age hierarchies. This gendered marketing of anti-ageing goods and services, combined with the US and Finnish men's ability to redefine what they do as not feminine and thus not anti-ageing, may help explain how 
they are able to engage in activities that they consider relevant for slowing down or alleviating the effects of ageing, and consume products for the same purpose. Men live in the same ageist culture in the global North as women, and thus are not immune to the dictate to fight the visible signs of growing old. Though the amount of anti-ageing products and services consumed in the USA and Finland may differ, the US and Finnish men's conceptions of anti-ageing in this study do not diverge significantly. This suggests that the idea of old age as a problem that individuals should fight to solve has suffused the global North. Men in the global North have money and time to fight against both things in order to maintain a privileged position: the potentially marginalising effects caused by ageing and emasculating effects of old age.

\section{NOTE}

1 All names are pseudonyms.

\section{References}

Adam, Paul Green 2014. Xocai Healthy Chocolate. Available online at http:// adampaulgreen.com/ [Accessed 5 May 2014].

Binstock, R. H., Fishman, J. R. and Johnson, T. E. 20o6. Anti-aging medicine and science: social implications. In Binstock, R. H. and George, L. K. (eds), Handbook of Aging and the Social Sciences. Academic Press, San Diego, California, 436-55.

Brooks, A. T. 2010. Aesthetic anti-ageing surgery and technology. Women's friend or foe? Sociology of Health and Illness, 32, 2, 238-57.

Calasanti, T. 2003. Theorizing age relations. In Biggs, S. and Lowenstein, A. (eds), The Need for Theory: Critical Approaches to Social Gerontology for the 2 Ist Century. Baywood, Amityville, New York, 199-218.

Calasanti, T. 2007. Bodacious berry, potency wood and the aging monster: gender and age relations in anti-aging ads. Social Forces, 86, 1, 335-55.

Calasanti, T. and King, N. 2005. Firming the floppy penis: age, class, and gender relations in the lives of old men. Men and Masculinities, 8, 1, 3-23.

Calasanti, T. and King, N. 2007. 'Beware of the estrogen assault': ideals of old manhood in anti-aging advertisements. Journal of Aging Studies, 2 1, 4, 357-68.

Calasanti, T., Pietilä, I., Ojala, H. and King, N. 2013. Men, bodily control, and health behaviors. The importance of age. Health Psychology, 32, 1, $15^{-23}$.

Collins, R., Chafetz, J. S., Blumberg, R. L., Coltrane, S. and Turner, J. H. 1993. Toward an integrated theory of gender stratification. Sociological Perspectives, $\mathbf{3} 6,3$, $185^{-216 .}$

Connell, R. W. 1995. Masculinities. Polity Press, Cambridge.

Connell, R. W. and Messerschmidt, J. W. 2005. Hegemonic masculinity. Rethinking the concept. Gender and Society, 19, 6, 829-59.

Conrad, P. 1994. Wellness as virtue: morality and the pursuit of health. Culture, Medicine and Psychiatry, 18, 3, 385-401.

Crawford, R. 1994. The boundaries of the self and the unhealthy other: reflections on health, culture and AIDS. Social Science and Medicine, 38, 10, 1347-65. 


\section{Hanna Ojala et al.}

Edley, N. and Wetherell, M. 1997. Jockeying for position: the construction of masculine identities. Discourse E् Society, 8, 2, 203-1 7.

Fishman, J. R., Settersten, R.A. Jr. and Flatt, M.A. 2010. In the vanguard of biomedicine? The curious and contradictory case of anti-ageing medicine. In Joyce, K. and Loe, M. (eds), Technogenerians: Studying Health and Illness Through an Ageing, Science, and Technology Lens. Blackwell, London, $25^{-37 .}$

George, D. R. and Whitehouse, P.J. 2011. Marketplace of memory: what the brain fitness technology industry says about us and how we can do better. The Gerontologist, 51, 5, 590-6.

Henwood, K., Gill, R. and McLean, C. 2002. The changing man. The Psychologist, 15 , $4,182-7$.

Hurd, L. 1999. 'We're not old!': older women's negotiation of aging and oldness. Journal of Aging Studies, 13, 4, 419-39.

Hurd Clarke, L. 2011 . Facing Age. Women Growing Older in Anti-aging Culture. Rowman and Littlefield, New York.

Hurd Clarke, L. and Griffin, M. 2007. The body natural and the body unnatural. Beauty work and aging. Journal of Aging Studies, 21, 3, 187-201.

Hurd Clarke, L. and Korotchenko, A. 2011 . Aging and the body: a review. Canadian Journal on Aging, 3o, 3, 495-510.

Intraceuticals 2014. Intraceuticals Clinic Locations. Available online at http://www. intraceuticals.com/countries/finland.html [Accessed 5 May 2014].

Juvonen, T. 2002. Varjoelämää ja julkisia salaisuuksia. Homoseksuaalisuuden rakentuminen sotienjälkeisessä Suomessa [Shadow Lives and Public Secrets.]. Vastapaino, Tampere, Finland.

King, N. and Calasanti, T. 2006. Empowering the old: critical gerontology and antiaging in a global context. In Baars, J., Phillipson, C., Dannefer, D. and Walker, A. (eds), Aging, Globalisation and Inequality: The New Critical Gerontology. Baywood, Amityville, New York, 139-57.

King, N. and Calasanti, T. 2013. Men's aging amidst intersecting relations of inequality. Sociology Compass, 7, 9, 699-710.

Kinnunen, T. 2010. 'A second youth': pursuing happiness and respectability through cosmetic surgery in Finland. In Joyce, K. and Loe, M. (eds), Technogenerians: Studying Health and Illness Through an Ageing, Science, and Technology Lens. Blackwell, London, $83-96$.

Lodge, A. C. and Umberson, D. 2013. Age and embodied masculinities: midlife gay and heterosexual men talk about their bodies. Journal of Aging Studies, 27, 3, $225^{-32 .}$

Luborsky, M. R. 1994. The identification and analysis of themes and patterns. In Gubrium, J. F. and Sankar, A. (eds), Qualitative Methods in Aging Research. Sage, Newbury Park, California, 189-210.

Marshall, B. L. and Katz, S. 20o6. From androgyny to androgens: re-sexing the aging body. In Calasanti, T. M. and Slevin, K. F. (eds), Age Matters. Routledge, New York, $75^{-97 .}$

Minichiello, V., Browne, J. and Kendig, H. 200o. Perceptions and consequences of ageism: views of older people. Ageing $\mathcal{E}$ Society, 20, 3, 253-78.

Paap, K. 2006. Working Construction. Why White Working-class Men Put Themselves-and the Labor Movement - in Harm's Way. Cornell University Press, Ithaca, New York.

Petersen, A. and Lupton, D. 1996. The New Public Health-Health and Self in the Age of Risk. Sage, London.

Phillipson, C. 2009. Reconstructing theories of aging: the impact of globalization on critical gerontology. In Bengtson, V. L., Silverstein, M., Putney, N. M. and Gans, D. (eds), Handbook of Theories of Aging. Springer, New York, 61 7-26. 
Pietilä, I. and Ojala, H. 2011. Acting age in the context of health: middle-aged working-class men talking about bodies and aging. Journal of Aging Studies, 25, 4, $380-9$.

Pomerantz, A. 1986. Extreme case formulations: a way of legitimizing claims. Human Studies, 9, 2/3, 219-29.

Racked 2014. Finnish Beauty Brand Lumene Launches New Anti-Aging Products. Available online at http://racked.com/archives/2011/o6/30/finlandbasedbeauty-brand-lumene-launches-new-antiaging-lines.php [Accessed 5 May 2014].

Sesderma 2014. Anti-aging products. Available online at http://www.sesderma.com/ finland/anti_aging_productsı.htm [Accessed 5 May 2014].

Skeggs, B. 2004. Class, Self, Culture. Routledge, London.

Slevin, K. F. 2008. Disciplining bodies: the aging experiences of older heterosexual and gay men. Generations 32, 1, 36-42.

Smirnova, M. H. 2012. A will to youth: the women's anti-aging elixir. Social Science E Medicine, 75, 7, $1236-43$.

Solimeo, S. 2008. Sex and gender in older adults' experience of Parkinson's disease. Journals of Gerontology: Psychological Sciences and Social Sciences, $\mathbf{6}_{3} \mathbf{B}, 1, \mathbf{S}_{42}{ }^{-8}$.

Taylor, S. J. and Bogdan, R. 1984. Introduction to Qualitative Research Methods: The Search for Meanings. Second edition, Wiley, New York.

Townsend, J., Godfrey, M. and Denby, T. 20o6. Heroines, villains, and victims: older people's perceptions of others. Ageing E्F Society, 26, 6, 883-9oo.

West, C. and Zimmerman, D. H. 1987. Doing gender. Gender E Society, 1, 2, $125^{-} 5^{1}$.

Wetherell, M. and Edley, N. 1999. Negotiating hegemonic masculinity. Imaginary positions and psycho-discursive practices. Feminism and Psychology, 9, 3, 335 $5^{-} 5^{6 .}$

WOSAAM 2014. About The WOSAAM. Available online at http://www.wosaam.ws/ aboutwosaam.htm [Accessed 5 May 2014].

Accepted I7 September 20I4; first published online 29 October 2014

Address for correspondence:

Hanna Ojala, School of Social Sciences and Humanities,

Kalevantie 5, 33014 University of Tampere, Finland.

E-mail: Hanna.L.Ojala@uta.fi 